\title{
Developing shrub fire behaviour models in an oceanic climate: Burning in the British Uplands
}

\author{
Davies G.M. \\ The University of Edinburgh, Centre for the Study of Environmental Change and \\ Sustainability, Edinburgh, EH9 3JN, Scotland, matt.davies@ed.ac.uk \\ Legg C.J. \\ The University of Edinburgh, Centre for the Study of Environmental Change and \\ Sustainability, Edinburgh, EH9 3JN, Scotland, colin.legg@ed.ac.uk \\ Smith A. \\ The Game Conservancy Trust, Drumochter Lodge, Dalwhinnie, Inverness-shire, PH2O \\ 1BE, Scotland, asmith@gct.org.uk \\ MacDonald A. \\ Scottish Natural Heritage, 2 Anderson Place, Edinburgh, EH6 5NP, Scotland, \\ ajmacdonald@treeline3m.freeserve.co.uk
}

\begin{abstract}
Prescribed burning of moorland vegetation in the UK is used to provide habitat for red grouse, a game bird, and to improve grazing for sheep and deer. The peak time of fire risk corresponds to the normal legal burning period of $1^{\text {st }}$ November $\left(1^{\text {st }}\right.$ October in Scotland) to $15^{\text {th }}$ April rather than a meteorologically-defined fire season.
\end{abstract}

Moorland fuels in the UK are unusual. They are dominated by Calluna vulgaris, which forms a dense, uniform canopy (though as stands age gaps become more frequent), and in which live material forms the majority of "available" fuel. The moisture content of live fuel plays a dominant role in determining fire behaviour. Weather in the UK uplands can vary rapidly from cold and wet, to sunny with drying winds and low atmospheric humidity. Frozen ground can prevent plants from replenishing water lost by transpiration. Fire behaviour can be difficult to predict and periods of significant wildfire activity can occur.

Data from fifteen experimental fires were used to build empirical relationships between rate of spread, windspeed and vegetation structure. Fires in the high fuel-loads responded much more strongly to increased windspeed. The high density of the fuel-bed in younger Calluna stands may have a limiting effect on the rate of fire spread. Redundancy Analysis highlights the importance of fuel moisture content and stand structural heterogeneity.

We tested the rate of spread predictions of BehavePlus and the Canadian Wildland Fire Information System (CWFIS). Predictions provided by BehavePlus were relatively good. The CWFIS was unable to predict rate of spread because the moisture content of live and dead Calluna was not accurately predicted by any of the moisture codes of the CWFIS. The system did detect a period of extreme risk associated with drought and wildfires during the spring of 2003. Multiple scales and causal factors of increased fire risk are discussed with reference to seasonal variation in the fuel moisture content of Calluna.

Keywords: BehavePlus, Calluna vulgaris, CWFIS, fire behaviour, fuel moisture, fuel structure, muirburn, rate of spread, UK, windspeed. 


\section{Introduction}

Prescribed burning is one of the most important land-management tools in the British uplands. A very variable climate makes fire behaviour difficult to predict and fire control is not always simple resulting in occasional escaped management fires and periods of significant wildfire activity.

A growing programme of research and the development of a fire danger rating system (Kitchen et al. this volume) is providing greater ability to predict both periods of maximum fire risk and fire behaviour for those undertaking management burns. This paper provides a brief description of the use of fire in the uplands of the UK, a description of what makes it unusual in an international context, an overview of recent research including some of the findings of the first set of truly replicated experimental fires in the UK and finally the results of testing existing fire behaviour models.

Wildland fire can be a contentious issue in the UK with ongoing arguments about the place for its use in the management of heathland areas (e.g. Sydes \& Miller 1988, Robertson et al. 2001, Tucker 2003). Despite this lack of agreement there lies the undeniable fact that it remains, with grazing, the principal management impact on heather moorland, a habitat type which covers c. $23 \%$ of the UK (Thompson et al. 1995). Throughout the past 200 years the use of fire to improve habitat for red grouse (Lagopus lagopus scoticus), red deer (Cervus elaphus) and sheep (Ovis aries) has been common practice. Traditional prescribed burning (known in Scotland as muirburning) aims to create a mosaic of small (c. $30 \mathrm{~m}$ wide) fires to provide feeding and nesting sites within each c. 2 ha grouse territory (Miller \& Watson 1978).

After a period of intense activity in the 1960s, moorland fire research in the UK has proceeded in fits and starts but, with a small number of notable exceptions (Kayll 1966, Thomas 1971, Hobbs \& Gimingham 1984, Hamilton 2000), the focus has been on characterising post-fire vegetation succession. Current uncertainties about the future of moorlands due to loss of heather cover (Mackey et al. 1998), climate change (Wessel et al. 2004), nitrogen deposition (Milne \& Hartley 2001) and reform of the Common Agricultural Policy (Silcock et al. 2003) mean that the need for greater knowledge of the behaviour and impact of fire has recently been recognised as important (Anon 2004).

The moorland fire situation in the UK is unusual compared with most other countries because our peak period of fire risk is related to the variable availability of dry and dead fuel before spring growth, and the period of legal prescribed burning. Prescribed burning is generally carried out by gamekeepers and graziers whilst most wildfires are either accidental or the result of escaped management fires, a smaller proportion are the result of arson. Very few fires can be classified as originating from 'natural' ignition sources, though they have been documented in the past (Allison 1954, Weatherall 1954), and conditions for such events remain infrequent.

In other areas of the world fire behaviour investigations have been focused on a meteorologically controlled "fire season" and fire risk in relatively hot, dry, summer conditions. The UK climate and the widespread use of muirburn as a management tool, together with the legislation surrounding heather and grass burning in the UK (summarised 
in SEERAD 2001 and MAFF 1994) mean that our interest in fire behaviour is focused on the core legal burning period of October $1^{\text {st }}$ to April. Weather in the UK uplands can vary rapidly from cold and wet, to warm and dry with low atmospheric humidity, strong drying winds and periods of physiological drought when the ground is frozen. Seasonal variations in fuel moisture can be large. In spring, winter damage to Calluna leaf cuticles by frost and wind abrasion (Grace 1990, Pitcairn et al. 1986) can combine with high potential evapotranspiration, frozen ground and xylem cavitation (Jackson et al. 1999) to produce unusually low fuel moisture contents (Davies 2005). Days suitable for burning are often limited which makes understanding fire behaviour essential if we are to enable landmanagers to make efficient use of time available without feeling under pressure to burn in unsafe conditions.

Heathland fuels in the UK are also unusual in an international context and a number of points should be noted:

- Calluna vulgaris is by far the dominant fuel and, in building phase (Gimingham 1988) stands, often forms dense, continuous, mono-specific canopies through which fire can easily spread. Higher fuel loads in mature or uneven-aged stands are often associated with greater structural heterogeneity and may be very patchy with significant canopy gaps. Greater heterogeneity in the fuel-bed with age means that relationships between increasing fuel load and fire behaviour may not be simple.

- There is a finite limit to the depth and loading of fine fuels due to shading and self thinning effects in the canopy. In older stands increased biomass takes the form of larger stems which lift the canopy up, away from ground level.

- The majority of fuel is live; indeed a key purpose of muirburning is to burn live heather shrubs in order to encourage, lush, vegetative regeneration. A typical 'Mature' Calluna canopy will only have around 10-30\% present as dead material. The fuel moisture regime is therefore significantly different from vegetation types where fire is driven by dead, dry fuels and this may have important dampening effects on fire behaviour (Catchpole \& Catchpole 1991).

- Fuel moisture contents (FMCs) are typically rather low for live fuel (65-100\%) and may become very low in late winter and early spring $(<45 \%)$, though these are still higher than dead fuels encountered elsewhere. Typical moisture values for the moss and litter layer are c. 150 to $>500 \%$. This material rarely burns during normal management fires, though it may be dry enough during summer or periods of prolonged drought and this can more than double the amount of available fuel.

- In younger stands quantities of dead fuels retained in the canopy are small but even here may play an important role in 'carrying' the fire; being drier they ignite first and dry and preheat live fuels. As the majority fuel in heathland is live, small variations in the amount or moisture content of this may be crucial (De Luis et al. 2004, Schwilk 2003).

Most fire behaviour models have been developed for fires in dead fuels of low moisture content, during a climatically defined fire season. British conditions may therefore challenge the performance of models. Our results should therefore be of interest to all researchers and model developers as well as to land-managers considering carrying out prescribed fire operations. Tools to forewarn land-managers of high risk periods are important for allowing advance preparation in an area where often the problem is getting a fire to ignite in the first place. 


\section{Methods}

Fifteen plots measuring $20 \mathrm{~m}$ long by $15 \mathrm{~m}$ wide were selected on Crubenmore Estate, on the edge of the Cairngorms National Park, in N.E. Scotland $\left(56^{\circ} 57^{\prime} \mathrm{N}, 04^{\circ} 15^{\prime} \mathrm{W}\right.$; OS Grid Ref. NN 6386). All sites were located on a slope of $<5-10 \%$. The vegetation of stands prior to burning was species poor, Calluna-dominated upland heath and comprised mostly closed stands of Calluna vulgaris with Vaccinium myrtillus and Vaccinium vitisidaea frequently occurring beneath the canopy. Stands contained a mixture of coarse grasses and sedges with Trichophorum cespitosum, Deschampsia flexuosa and Molinia caerulea common, though none of these formed a significant component of the total fuel load. Most stands of the building phase (Gimingham 1988) and older were underlain by more or less continuous mats of pleurocarpous mosses.

Sites were visually assigned to one of three fuel loading categories: High, Medium or Low. Firebreaks were swiped and burnt around the outside of each plot. Each plot was intensively surveyed beforehand using the FuelRule technique (Davies 2005) to determine its pre-fire fuel loading and structure. Fuel moisture samples from the heather canopy and the moss/litter layer were taken immediately before burning. During fires we measured rate of spread and flame height using $2.5 \mathrm{~m}$ marker posts down the centre of each plot as a reference. Fires were lit along the down-wind edge of a plot using a drip torch to create a single $15 \mathrm{~m}$ wide ignition line. Post-fire we re-surveyed plots to estimate burnt biomass thus allowing the calculation of fireline intensity as described by Alexander (1982). This paper focuses on understanding variation in rate of spread (RoS).

The data collected were used to construct empirical models of fire spread. We tested the predictions of BehavePlus (Andrews et al. 2005) by constructing fuel models for each of the fifteen fires individually, three models for the high, medium and low fuel loadings, and a single model for the mean conditions in stands as a whole. Finally we examined the relationship between observed rates of spread and the Initial Spread Index (ISI) of the Canadian Forest Fire Weather Index System (CFFWIS) (Van Wagner 1987) and the predictions of spread rate given by grass and Jack pine fuel models of the Canadian Fire Behaviour Prediction Sytem (FBP) (Forestry Canada 1992). The latter was included as it is utilised in the Met Office Fire Severity Index (see Kitchen et al. this volume).

\section{Results}

Rate of spread, fireline intensity and flame properties varied enormously: RoS from 0.5 to $12.6 \mathrm{~m} \mathrm{~min}^{-1}$, intensity from 75 to $3388 \mathrm{~kW} \mathrm{~m}^{-1}$ and flame height from roughly half a metre to just under two metres. Significant differences in fire behaviour existed both between and within fuel categories for all three sets of behaviour characteristics. Variability was especially noticeable in the 'High' category plots.

\section{Modelling Rate of Spread}

The linear regression of rate of spread on the derived variable (mean height ${ }^{2} \times$ windspeed) had an $R^{2}$ (adj) of 0.81, but predicted negative RoS at zero windspeed (Equation. 1).

$$
R=-0.147+0.00110 \times h^{2} \times v
$$

Where $R=$ rate of spread $\left(\mathrm{m} \mathrm{min}^{-1}\right) ; h=$ mean canopy height $(\mathrm{m}) ;$ and $v=$ wind speed $\left(\mathrm{m} \mathrm{s}^{-1}\right)$ 
Additional problems of negative confidence intervals and greater variance at high rates of spread can be avoided if RoS is first log transformed. The best single, untransformed predictor of In RoS was the FuelRule (Davies 2005) value 'CDI' (Canopy Density Index, related to canopy density and fuel load-more negative values correspond to higher bulk density and reduced total fuel load). This gave a regression with an $R^{2} 0.69$ for $\ln (\operatorname{RoS})$ (Equation 2, Figure 1) indicating that fuel loading and structure is of great importance in determining fire behaviour.

$$
\ln (\mathrm{R})=3.91+7.65 \times \mathrm{d}
$$

Where $R=$ rate of spread $\left(\mathrm{m} \mathrm{min}^{-1}\right)$; and $d=\mathrm{CDI}$

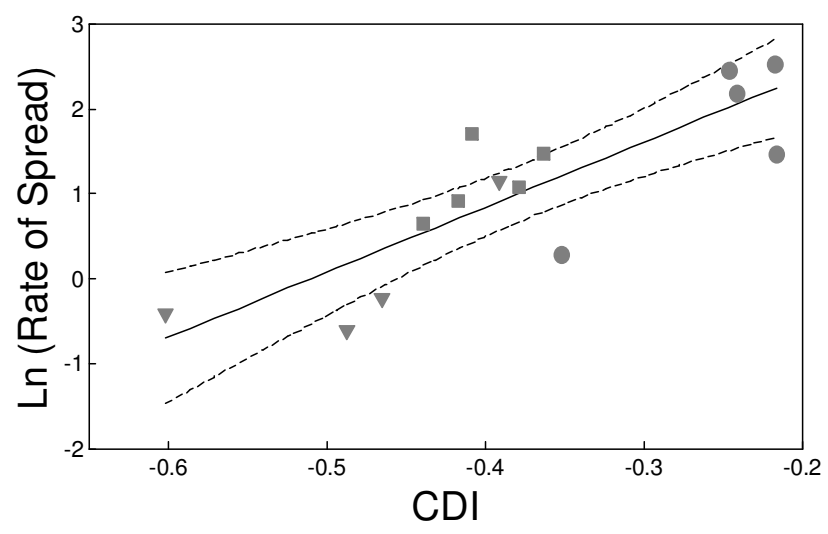

Figure 1: Regression of $\ln \operatorname{RoS}\left(\mathrm{m} \mathrm{min}^{-1}\right)$ on the FuelRule variable 'CDI'. Dashed lines are 95\% confidence intervals. Triangles, squares and circles represent Low, Medium and High fuel groups respectively.

Best subsets regression using a variety of predictors yielded Equation 3 which has an $R^{2}$ (adj) of 0.77. Figure 2 shows predicted versus actual spread rates for this equation.

$$
\ln (R)=1.39+0.000125 h^{2} \cdot v+9.38 d \times \sigma_{d}
$$

Where $\mathrm{R}=$ rate of spread (m min-1); h = mean canopy height $(\mathrm{m}) ; \mathrm{v}=$ wind speed $(\mathrm{m} \mathrm{s}-1) ; \mathrm{d}=\mathrm{CDI}$; and $\sigma_{\mathrm{d}}=$ standard deviation of CDI, $\mathrm{d}$.

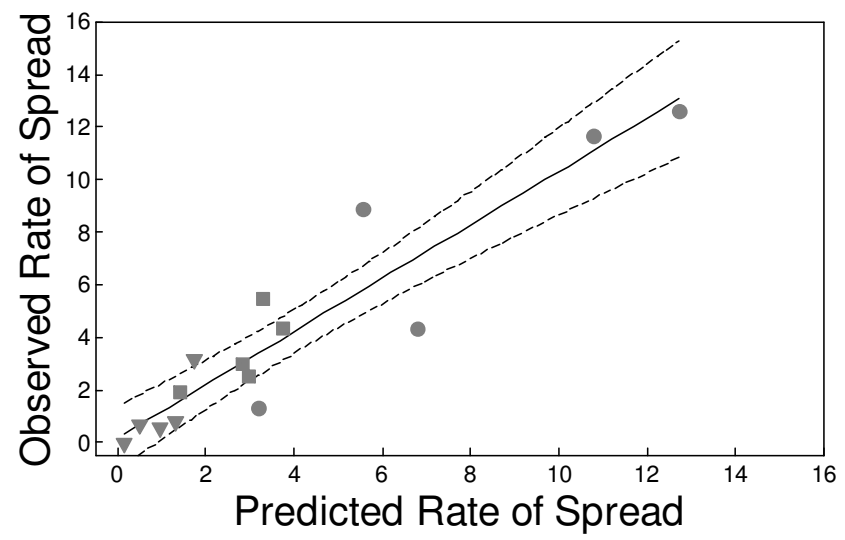

Figure 2: Rate of spread $\left(\mathrm{m} \mathrm{min}^{-1}\right)$ predicted by Equation 3 versus observed values. Triangles, squares and circles correspond to Low, Medium and High fuel loadings. The dashed lines show $95 \%$ confidence intervals. 
Examination of Equations 1-3 reveals that the models which best explain variation in fire RoS tend to be those where windspeed and canopy height (which is strongly correlated with fuel loading, $(r=0.96)$ and stand age and structure) are combined in an integrated factor which is more strongly controlled by variations in fuel structure. In Equations 1 and 3 the effect of windspeed is increased in plots with greater canopy height. Figure 3 shows the relationship between RoS and windspeed for separate fuel groups; higher loadings respond to wind much more strongly than 'Medium' and 'Low' fuel groups.

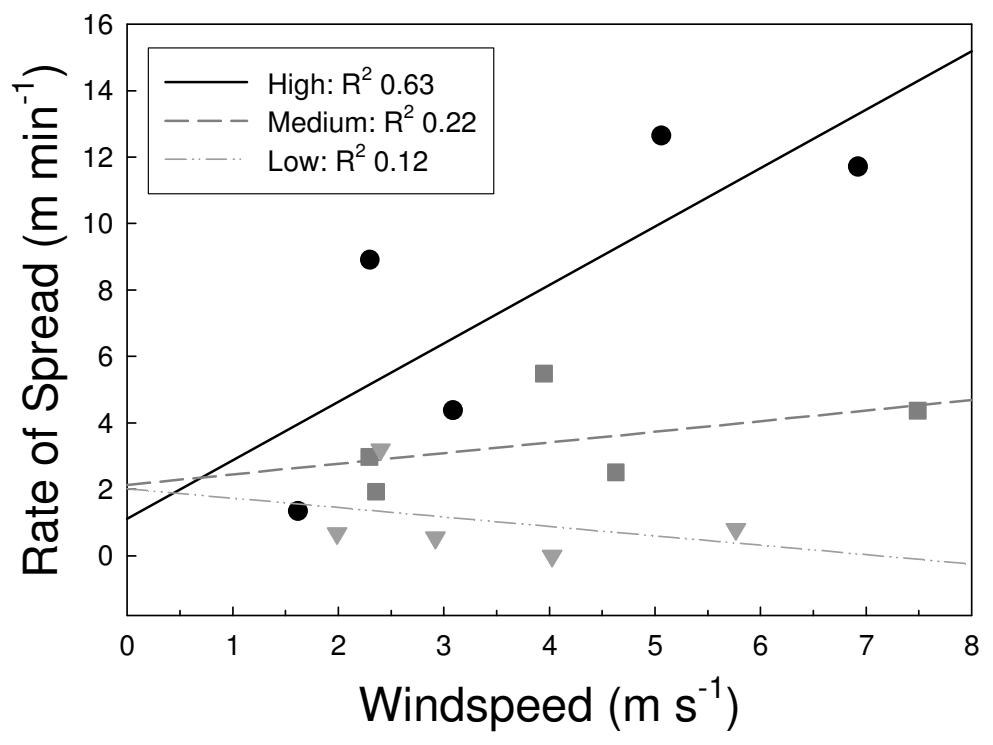

Figure 3: Rate of spread against windspeed. Individual fuel groups are shown: High (circles, solid line), Medium (squares, dashed line) and Low (triangles, dotted line).

\section{Redundancy Analysis}

Redundancy Analysis (RDA) established linkages between environmental variables and fire behaviour with certain predictors, including canopy height, CDI and its standard deviation and windspeed, consistently emerging as important. RDA with forward selection of predictor variables was used to investigate the influence of all predictors recorded on various elements of fire behaviour (Figure 4).

Rate of spread and fireline intensity are correlated with windspeed but are more strongly linked with plot measures associated with the nature of the fuel-bed. Of all the predictor variables shown only 'CDI' was statistically significant (Monte-Carlo permutation test, $P=$ 0.001), where an increased CDI corresponds to a less dense canopy and faster rates of spread. The directions of other arrows are of interest as they show the manner in which predictors force change in fire behaviour parameters. Greater flame lengths, for instance, are strongly related to higher fuel loadings while an increase in the proportion of dead fuel seems to slightly encourage faster rates of spread.

Fuel moisture content did not have a statistically significant effect $(\mathrm{P}>0.05)$ in our regression analyses. The RDA, however, confirms that FMC plays an important role in fire behaviour with increased moisture contents leading to slower moving, less intense fires with smaller flames. Increased standard deviations of 'CDI' also have a negative impact on fire RoS with patchier fuel beds also giving rise to slower moving fires. 


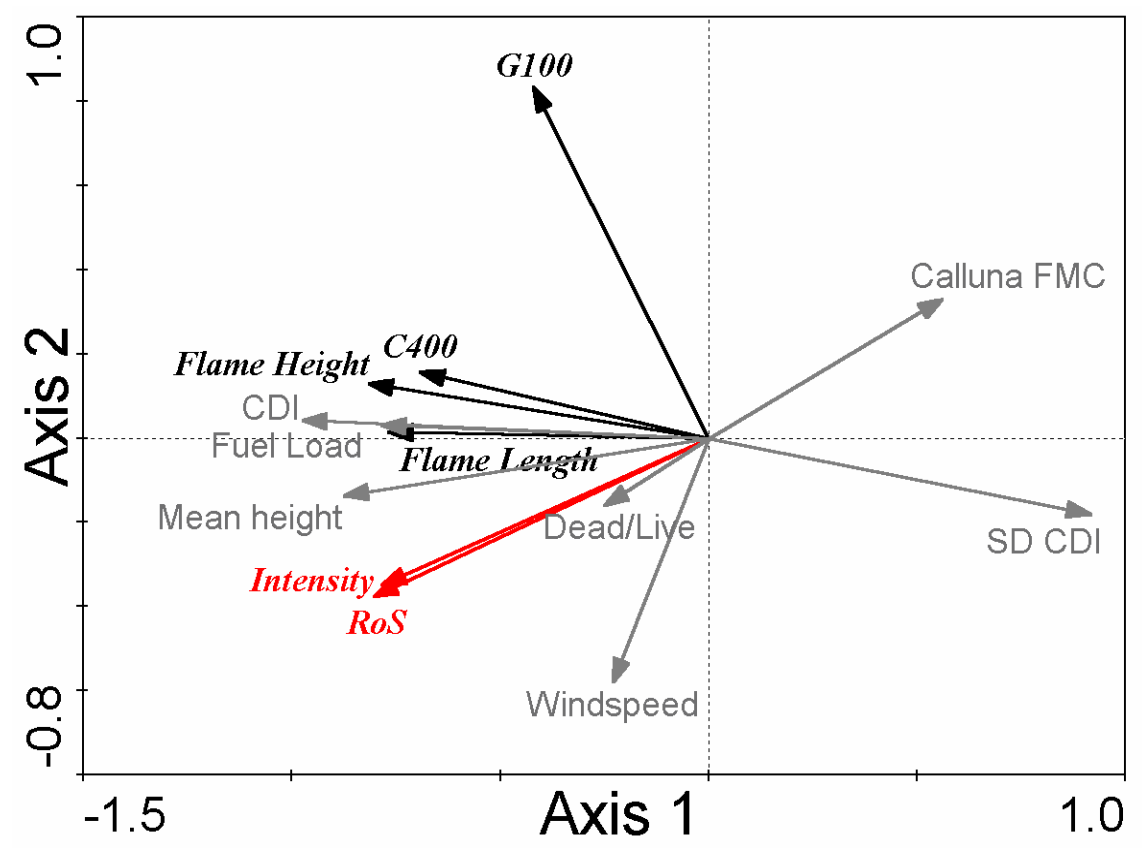

Figure 4: Results of RDA of fire characteristics (response variables) on fuel and weather characteristics (predictor variables). Axes 1 and 2 together explained 70\% of the variation in fire behaviour, 53\% was explained by axis 1 alone. CDI = Canopy Density Index; $\mathrm{C} 400=$ duration of temperatures above $400{ }^{\circ} \mathrm{C}$ in the canopy; $\mathrm{G} 100=$ duration of temperatures above $100{ }^{\circ} \mathrm{C}$ at ground level.

\section{Testing fire spread models}

BehavePlus performed reasonably well in predicting rate of spread when each fire was predicted using an individually-calculated fuel model for each stand (Figure 5a), however when we tried using a single fuel model for all stands the results were extremely poor. Three separate models constructed for mean conditions found in High, Medium and Low fuel loading plots gave relatively good results (Figure 5b). Although individual fires were not particularly accurately predicted the general trend appeared to be good with the line of perfect agreement lying within the $95 \%$ confidence intervals for the regression line of observed on predicted values (Figure 5).
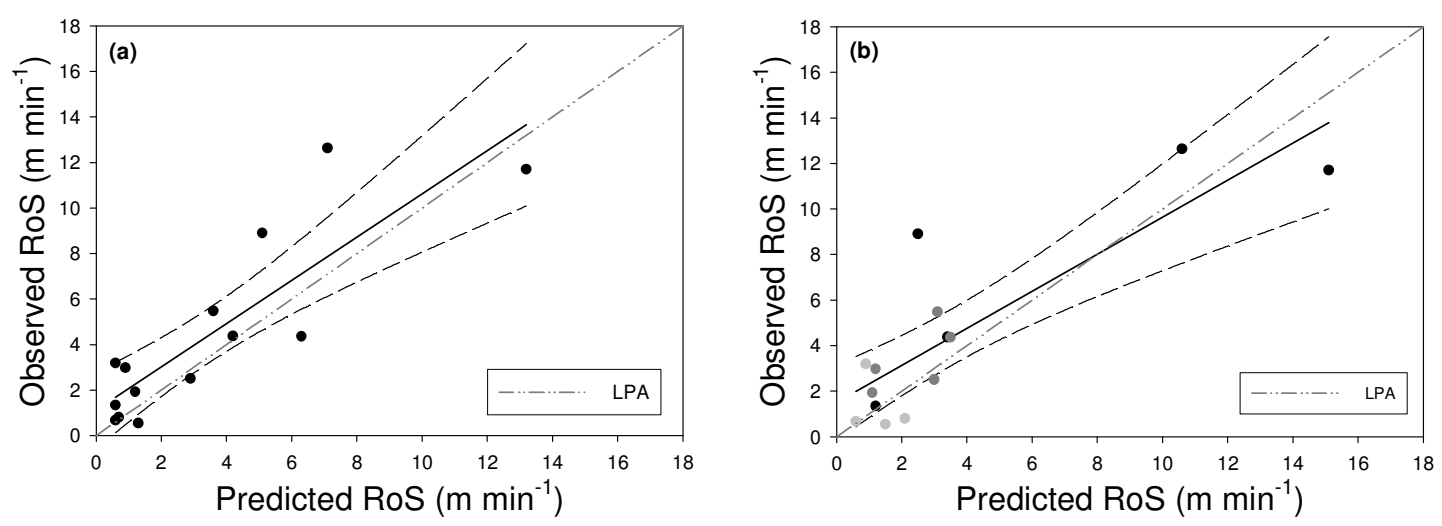

Figure 5: Predicted rates of spread from BehavePlus for 14 experimental fires using (a) individual fuel models for each plot and (b) grouped fuel models for High, Medium and Low fuel loadings. The figure shows the regression of observed on predicted values together with $95 \%$ confidence intervals in comparison with the line of perfect agreement (LPA). In (b) High, Medium and Low fuel loads are shown in black, dark grey and grey respectively. 
The performance of the CWFIS was disappointing with no significant relationship existing between observed RoS and ISI. The same is also true for RoS predicted using the Jackpine and grass $(\mathrm{O} 1 \mathrm{~b})$ fuel models (Figure 6). It is important to note that these fires occurred over an extremely small range of predicted ISI, BUI and FWI; maximum values calculated were $4.8,6.8$ and 3.3 respectively.

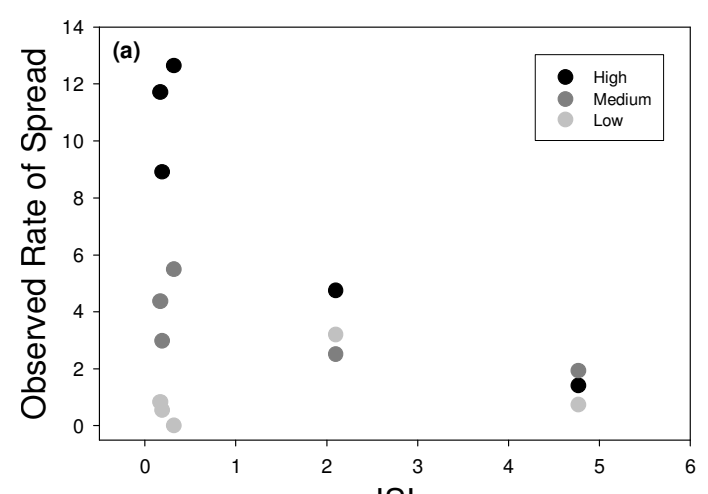

ISI

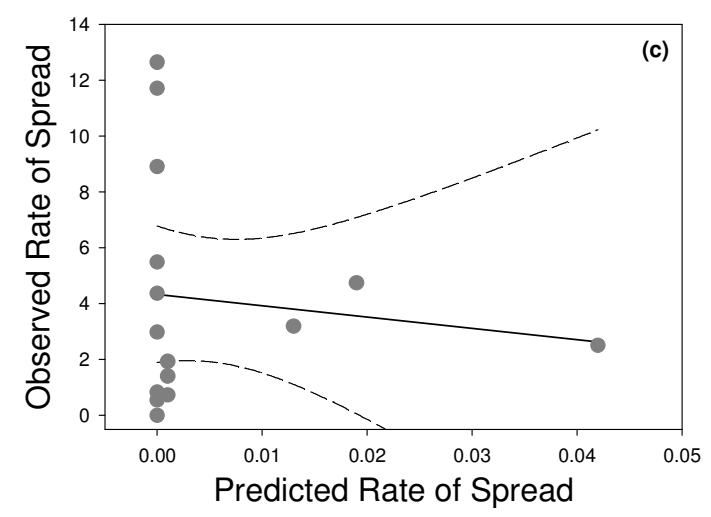

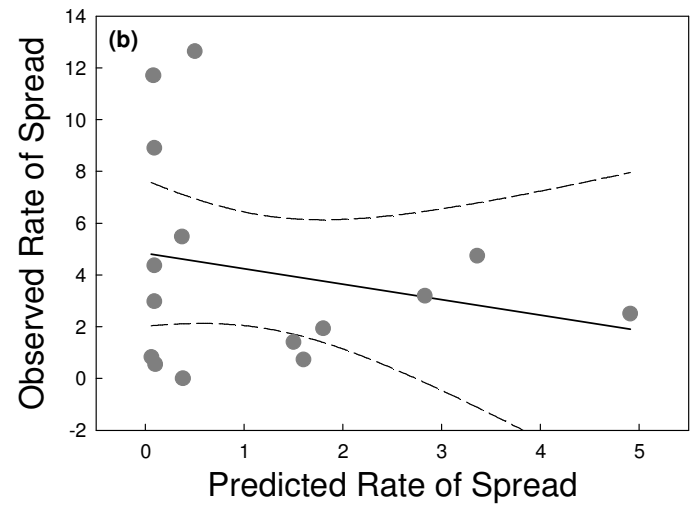

Predicted Rate of Spread

Figure 6: Observed RoS for our fires plotted against daily ISI values (a). Separate fuel loading categories are shown: High (black), Medium (grey) and Low (light grey). RoS predicted using the O1b grass (b) and C3 Jack pine (c) are also shown.

\section{Discussion}

There have been few studies of fire behaviour in heather moorland fuels in the UK and those that do exist have been primarily concerned with documenting fire temperatures so we have little data with which to compare our results. Our spread rates and intensities compare favourably with those recorded by Molina \& Linares (1998), De Luis et al. (2004) and Fernandes (2001) in Mediterranean shrubland experimental fires. Our values are, however, around half the highest recorded by Bruce \& Servant (2003) in the understory of Scots pine (Pinus sylvestris) woodland where the Calluna was both old and of extremely high loading.

We have been able to construct simple equations which relate vegetation height and windspeed to rate of spread though we know however that these cannot be the only things affecting fire behaviour. The equations presented here reflect variation within a limited range of conditions during low-medium fire risk periods during the burning season. It is notable that fuel moisture is absent from the equations presented here, though from 
previous work and from Figure 4 we know that this must have some effect. The relatively narrow range of conditions in which we conducted our burns may explain the absence of statistical significance and future work will place emphasis on defining the influence of FMC. This will be complicated however by independent variation in the moisture content of dead and live material and non-linearity in fire responses.

The strong correlation between 'CDI' and RoS (Figures 1 and 4) demonstrates that fuel structure is as important, if not more so than, fuel load in governing the rate at which fuels can burn. Less dense, better aerated canopies, with higher proportions of available fuel and lower FMC are certainly able to burn fiercely and spread faster. Canopy Density Index controls fire behaviour, not just because it is strongly linked to canopy density, but because it is actually an integrated factor relating to several stand/fuel characteristics.

Greater variability in behaviour within and between fires in 'High' plots is possibly due to an increased sensitivity to windspeed in more 'gappy' stands. It is also important to note the role that the standard deviation of CDI plays suggesting that discontinuities in the fuel bed will slow spread rates and lower fireline intensities. For this reason the spread rate of older stands in low wind conditions is low and thus canopy density is one thing but patchiness is quite another.

It is interesting to note from Figure 3 that at low windspeeds 'High' fuel loadings have lower spread rates than many 'Medium' or 'Low' fuel groups. Higher windspeeds flatten flames allowing them to bridge canopy gaps thus increasing heat transfer and fire spread through what is already taller, better aerated, drier fuel bed. Higher windspeeds also force convection columns closer to the ground with hot smoke plumes sometimes forced to travel over and through fuel beds for considerable distances. Figure 3 also suggests that high crown density limits the development of high fire intensity and rate of spread in 'Low' and 'Medium' fuels. Higher FMC in these stands also means that they require a greater amount of heat to reach ignition temperature, and greater quantities of smothering water vapour are produced (Pompe \& Vines 1966, Catchpole \& Catchpole 1991). The deep glowing ember beds seen behind the advancing flaming combustion front in such stands provides visual evidence of lower rates of combustion.

\section{Fire behaviour models}

Our results show that BehavePlus works relatively well, as would be expected for a semiempirical model based on generally applicable principles of heat transfer. The variability in behaviour between different fuel types is however highlighted by the fact that a single fuel model for Calluna was not adequate and although three fuel-group models performed reasonably the accuracy of predictions was low. There is evidence of increasing variability in "real" fire spread rates with increased predicted spread for both modelling approaches.

The CWFIS was disappointing, being unable to detect changes in behaviour at the management fire scale. The Fine Fuel Moisture Code (FFMC), Duff Moisture Code (DMC) and Drought Code (DC) are meteorologically defined variables representing the moisture content of dead fine fuels, litter and deep organic matter. The FFMC is a key driver of ISI and thus predictions of RoS. Davies (2005) showed that the relationship between Calluna canopy moisture content (which is dominated by live, green shoots) and 
FFMC is weak (Figure 7). It is therefore not surprising to find that the CWFIS performs badly for fires in 'normal' prescribed burning conditions.
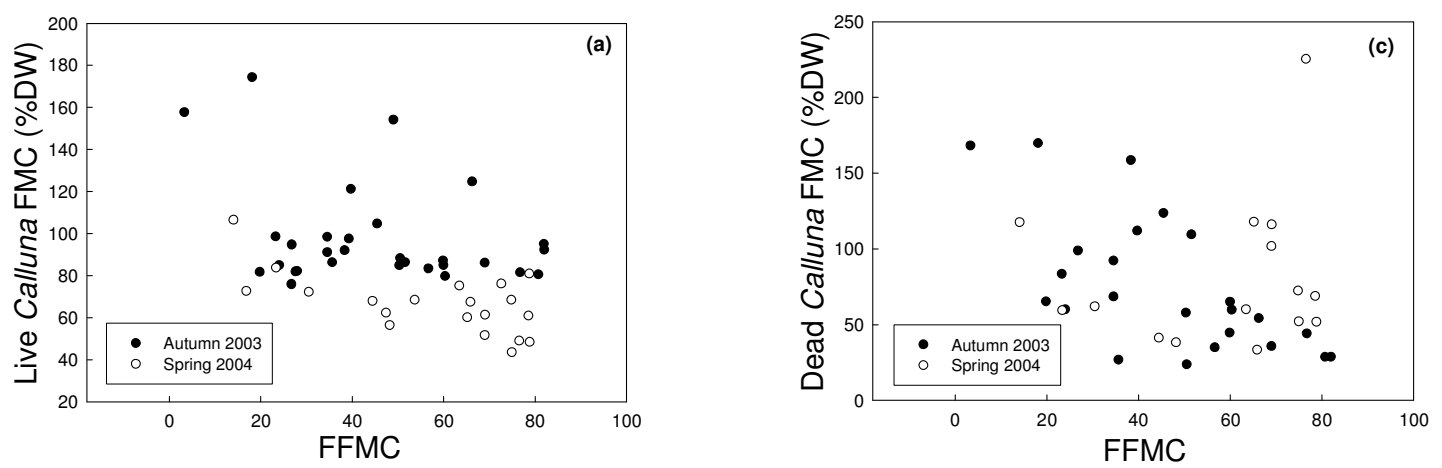

Figure 7: The prediction of FMC by the CWFIS during autumn 2003 and spring 2004: (a) live and (b) dead Calluna versus the FFMC. Note that high values of FFMC represent low moisture content.

At our experimental site, and the majority of sites in the UK, Calluna stands are not only dominated by live material but also sit on deep layers of peat which, even during periods of low rainfall in summer, normally retain enough water to allow Calluna plants to maintain their moisture status. Thus the FFMC, DMC, DC, and hence Build-up Index (BUI), are rendered relatively poor at predicting changes in live moisture content despite the fact the latter have been shown to do so successfully elsewhere in the context of summer drought (Castro et al. 2003, Viegas et al. 2001). Even more importantly FFMC appears to bare little relationship to dead FMC which, in our systems, is suspended in the canopy and so the model predictions do not even adequately account for the moisture status of this crucial fuel component. One should also remember that the analysis of our fires failed to show FMC as having a statistically significant control on fire behaviour partly because it did not vary greatly between most fires. This is a problem for a prediction system that relies heavily on fuel moisture for the estimation of rates of spread.

As was pointed out earlier, while fires occurring during hot, dry, drought periods in late spring and summer are of some concern, most of the highest levels of fire risk are during the autumn and spring prescribed burning periods (Kitchen et al. this volume).

Meteorological conditions during this time generally give low FWI/ISI values, but the innate flammability of Calluna and a helping hand from an ignition source allows intense fires to develop. Also of importance is the fact that in early spring live Calluna FMCs may be extremely low for living plant material. This follows a period of dormancy and overwinter damage to the cuticle from wind abrasion and blown ice crystals which leads to 'winter browning' (Bannister 1964) and an inability to prevent water loss by stomatal closure. Dry sunny periods during the spring, when the ground remains frozen, means Calluna FMCs can drop even lower leading to potentially extreme fire behaviour. The FFMC in fact worked slightly better for live fuels in spring (Figure 7) suggesting that when root activity is limited and cuticles damaged they behave more like dead fuels.

Davies (2005) recorded seasonal changes in FMC and found evidence of sharp drops in fuel moisture associated with frozen ground and dry, sunny weather in the spring of 2004 (Figure 8). The spring of 2003 saw exactly these conditions over large areas of the UK for prolonged periods and an unprecedented number of wildfires developed. While some of 
these were a result of accidents or even arson, a significant number were lit by landmanagers who were caught by surprise by the high intensity fires which subsequently developed. Clearly in these conditions low live FMC becomes critical in determining fire behaviour and provides evidence of non-linearity in fire risk.
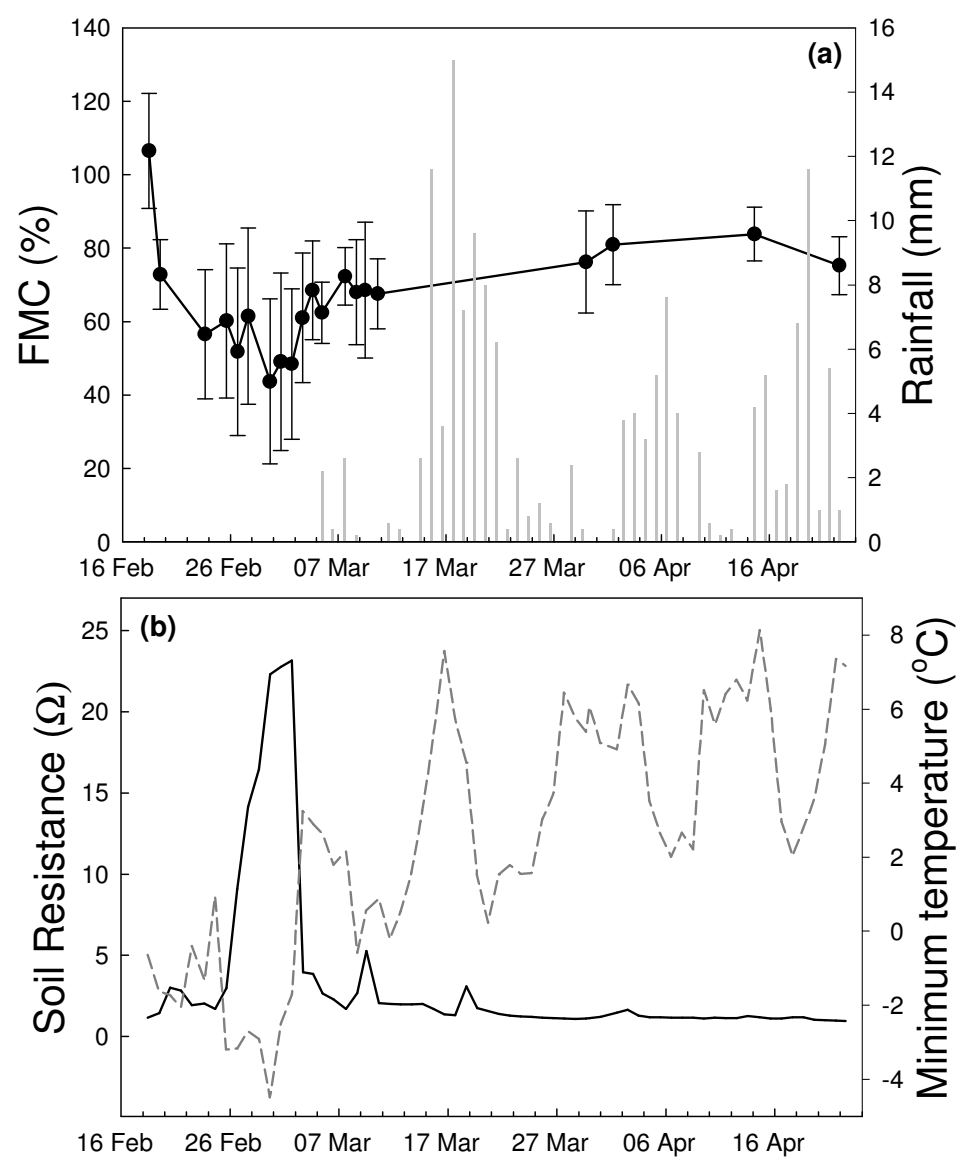

Figure 8: Variation in the FMC of live and dead Calluna canopy material during the spring of 2004: (a) live Calluna, error bars are \pm 1 standard deviation, bars are total daily rainfall (right-hand axis); (b) changes in soil resistance with peaks corresponding to frozen ground (solid line), the dashed line shows the mean minimum temperature over the previous 24 hours.

The CWFIS successfully identified the period of high fire risk associated with prolonged drought and warm day-time temperatures during the spring of 2003 (Figure 9); an FWI value of $16-27$ corresponding to a high fire danger rating according to Van Wagner (1987). These findings suggest a number of things. First, that the CWFIS is capable of identifying periods of extreme risk in the UK (see also Kitchen et al. this volume). Second, that fire behaviour in the UK operates at a number of different scales. Clearly, the model is not capable of detecting the variation in behaviour associated with fire during 'normal' prescribed burning conditions nor does it account for all the causes of raised fire risk during periods such as the spring of 2003. The FWI was only successful in detecting the high fire risk due to the period low rainfall and high temperatures not because of the significant impacts of lack of winter snow cover and frozen ground due to low night-time temperatures. Third, as has been commented on by other authors (e.g. Schoenberg et al. 2003), there exist significant non-lineararities in fire behaviour, especially with regards to the influence of FMC: small changes may induce leaps in fire behaviour when other conditions vary (windspeed, topography, dead-live fuel ratio, bulk density, etc.). Finally, 
while the CWFIS seems capable of predicting periods of extreme risk, there needs to be either a separate model to predict variation in fire behaviour during typical prescribed burning conditions, or significant work done on building an FFMC which works well for UK conditions

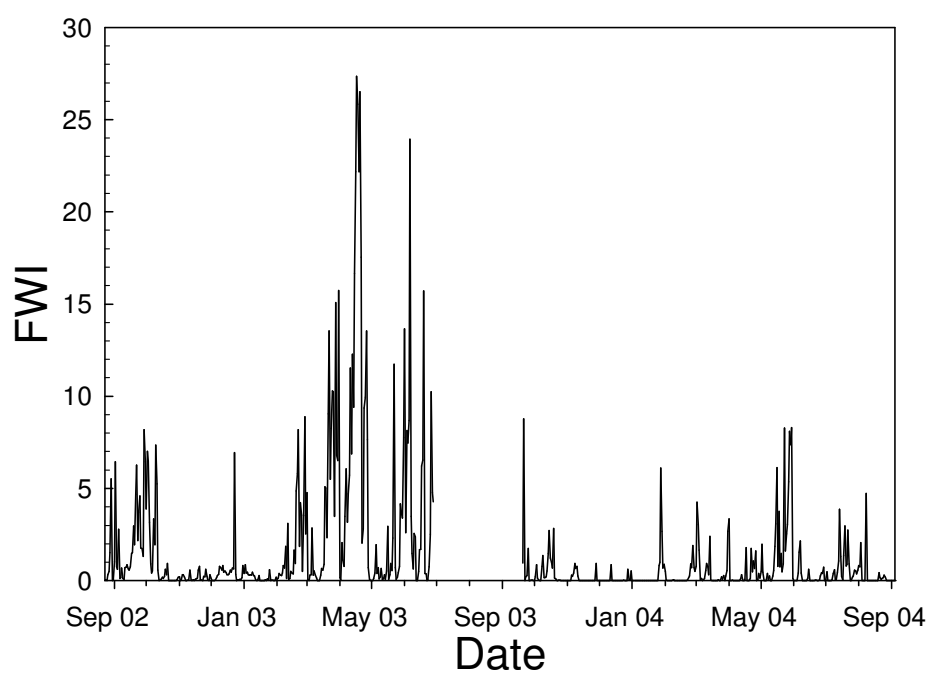

Figure 9: Daily values of the FWI from autumn 2002 to the end of summer 2004 calculated from met data collected a station located $10 \mathrm{~km}$ from the experimental site. Note the pronounced peak for spring 2003.

\section{Management Implications}

Due to a short burning season and high labour costs many land-managers feel under pressure to burn older heather to try and bring it back into productivity. Our results highlight some of the difficulties involved in burning such stands safely. Fires in older fuels (which correlate well with our 'High' loading category) burn faster and hotter and are more prone to rapid changes in behaviour associated with fluctuating weather conditions (particularly changing windspeeds). We must now begin to question whether existing blanket prescriptions of $30 \mathrm{~m}$ wide fires and the traditional, almost exclusive, use of headfires are appropriate. During large parts of the burning season fires can be completed safely and effectively in a very wide range of conditions provided the appropriate tools and tactics are used. Land-managers in the UK have a responsibility to ensure that the way prescribed burning is performed makes best possible use of our growing knowledge of fire behaviour. As scientists it is our job, however, to communicate our findings, to develop new tools that make prescribed burning easier and safer, and to constantly seek to build on the considerable experience of the land-management community.

Future work in the UK (Kitchen et al. this volume) will generate predictive relationships between fuels, weather, fires and their impacts to enable land-managers to complete burn programmes with a greater understanding of likely fire behaviour and impact and thus burn not only more safely but also more effectively, making best use of available time and labour whilst minimising potential environmental damage. The relationships defined here, if corroborated and expanded by further observations, can be used to create a more scientific foundation for management advice. 


\section{References}

Andrews P.L., Bevins C.D., Seli R.C., 2005. BehavePlus fire modelling system Version 3.0: User's Guide. General Technical Report RMRS-GTR-106WWW Revised. USDA Forest Service, Rocky Mountain Research Station. Ogden, Utah.

Anon 2004., Summary statement. Terrestrial Environmental Change in the Highlands and Islands: From Mountain Summits to Coasts. Inverness, 26-28 March 2004. UHI Millennium Institute. Perth

Alexander M.E., 1982. Calculating and interpreting forest fire intensities. Can. J. Botany 60, 349-357.

Allison B.J.,1954. Lightning and forest fires at Rosedale Tarn. Journal of the Forestry Commission 1952-1954, 23, 65-66.

Bannister P., 1964. The water relations of certain heath plants with reference to their ecological amplitude. III. Experimental studies: general conclusions. J. Ecol. 52, 499-509.

Bruce M.A., Servant G., 2003. Fire and Pinewood Ecology in Scotland: a Summary of Recent Research at Glen Tanar Estate, Aberdeenshire. Scottish Forestry 57, 33-38.

Castro F.X., Tudela A., Sebastia M.T.,2003. Modelling moisture content in shrubs to predict fire risk in Catalonia (Spain). Agr. Forest Meteorol. 116, 49-59.

Catchpole E.A., Catchpole W.R., 1991. Modelling moisture damping for fire spread in a mixture of live and dead fuels. Int. J. Wildland Fire 1, 101-106.

Davies G.M., 2005. Fire behaviour and impact on heather moorland. Unpublished PhD Thesis, University of Edinburgh.

De Luis M., Baeza M.J., Raventos J., Gonzalez-Hidalgo J.C.G., 2004. Fuel characteristics and fire behaviour in mature Mediterranean gorse shrublands. Int. J. Wildland Fire 13, 7987.

Fernandes P.M., 2001. Fire spread prediction in shrub fuels in Portugal. For. Ecol. Manag. $144,67-74$.

Forestry Canada, Fire Danger Group, 1992. Development and Structure of the Canadian Forest Fire Behaviour Prediction System. Information Report ST-X-3. Forestry Canada, Ottawa.

Gimingham C.H., 1988. A reappraisal of cyclical processes in Calluna heath, Vegetatio 77, 61-64.

Grace J., 1990. Cuticular water loss unlikely to explain tree-line in Scotland. Oecologia 84, 64-68. 
Hamilton A., 2000. The characteristics and effects of management fire on blanket-bog vegetation in north-west Scotland. Unpublished PhD Thesis, University of Edinburgh.

Hobbs R.J., Gimingham C.H., 1984. Studies on Fire in Scottish Heathland Communities: I. Fire Characteristics. J. Ecol. 72, 223-240.

Jackson G.E., Irvine J., Grace J., 1999. Xylem acoustic emissions and water relations of Calluna vulgaris L. at two climatological regions of Britain. Plant Ecol. 140, 3-14.

Kayll A.J., 1966. Some characteristics of heath fires in north-east Scotland. J. Appl. Ecol. 3, 29-40.

Kitchen K., Marno P., Legg C., Bruce M., Davies G.M., this volume. Developing a Fire Danger Rating System for the United Kingdom. Proceedings of the V International Conference on Forest Fire Research.

Mackey E.C, Shewry M.C., Tudor G.J., 1998. Land Cover Change: Scotland from the 1940 's to the 1980's. Stationary Office, Edinburgh.

MAFF, 1994. The Heather and Grass Burning Code. MAFF Publications, London. Available from: http://www.defra.gov.uk/rural/uplands/burning.htm [Accessed 06 Jun 06].

Milne J.A., Hartley S.E., 2001. Upland Plant Communities - sensitivity to change. Catena, 42, 333-343.

Miller G.R., Watson A., 1978. Territories and the food plant of individual red grouse. I. Territory size, number of mates and brood size compared with the abundance, production and diversity of heather. J. Anim. Ecol. 47, 293-305.

Molina M.J., Llinares J.V., 1998. Relationships between fire behaviour, weather conditions and fire intensity parameters in experimental summer fires in Valencia shrublands. In: Viegas D.X. (Ed.) Proceedings of the III International Conference on Forest Fire Research and the 14th Conference on Fire and Forest Meteorology. Volume I. Luso, Coimbra, Portugal 16-20th November 1998.

Pitcairn C.E.R., Jeffree C.E., Grace J., 1986. Influence of polishing and abrasion on the diffusive conductance of leaf surface of Festuca arundinacea Schreb. Plant Cell Environ. 9, 191-196.

Pompe A., Vines R.G., 1966. The influence of moisture on the combustion of leaves. Australian Forestry 30, 231-241.

Robertson P.A., Park K.J., Barton A.F., 2001. Loss of heather Calluna vulgaris moorland in the Scottish uplands: the role of red grouse Lagopus lagopus scoticus management. Wildlife Biol. 7, 11-16.

Schwilk D.W., 2003. Flammability is a niche construction trait: canopy architecture affects fire intensity. Am. Nat. 162, 725-733. 
Schoenberg F.P., Peng R., Huang Z., Rundel P., 2003. Detection of non-linearities in the dependence of burn area on fuel age and climatic variables. Int. J. Wildland Fire 12, 1-6.

SEERAD, 2001. The Muirburn Code. Scottish Executive, Edinburgh.

Available from: http://www.scotland.gov.uk/library3/environment/mbcd-00.asp [Accessed 26 Jun 06].

Silcock P, Swales V., Manley W., 2003. The Potential Environmental Impacts of the CAP Reform Agreement. Final Report for Department for Environment, Food \& Rural Affairs. Unpublished report.

Available from: http://statistics.defra.gov.uk/esg/reports/capreform3/default.asp [Accessed 26 Jun 06].

Sydes C., Miller G.R., 1988. Range Management and Nature Conservation in the British Uplands. In: Usher M.B., Thompson D.B.A. (Eds.) Ecological Change in the Uplands. Oxford, Blackwell, pp. 323-337.

Thomas P.H., 1971. Rates of spread of some wind-driven fires. Forestry 44, 155-175.

Thompson D.B.A., MacDonald A.J., Marsden J.H., Galbraith C.A., 1995. Upland heather moorland in Great Britain: A review of international importance, vegetation change and some objectives for nature conservation. Biol. Conserv. 71, 163-178.

Tucker D., 2003. Review of the impacts of heather and grassland burning in the uplands on soils, hydrology and biodiversity. English Nature Research Report Number 550.

Peterborough, English Nature.

Van Wagner C.E., 1987. Development and Structure of the Canadian Forest Fire Weather Index System. Forestry Technical Report 35. Canadian Forestry Service, Ottawa.

Viegas D.X., Pinol J., Viegas M.T., Ogaya R., 2001. Estimating live fine fuel moisture content using meteorologically-based indices. Int. J. Wildland Fire 10, 223-240.

Weatherall J., 1954. Lightning and forest fire at Langdale Forest. Journal of the Forestry Commission 1952-1954. 23, 66-67.

Wessel W.W., Tietema A., Beier C., Emmet B.A., Penuelas J., Riis-Nielsen T., 2004. A qualitative ecosystem assessment for different shrublands in Western Europe under impact of climate change. Ecosystems 7, 662-671. 